Tohoku J. exp. Med., 1982, 136, 157-162

\title{
Effect of Vagal Tone on Airway Smooth Muscle Force and Peribronchial Pressure in Dogs
}

\author{
Ryo Kikuchi, Hidetada Sasaki, Masao Nakamura and \\ Tamotsu Takishima* \\ The First Department of Internal Medicine, Tohoku University \\ School of Medicine, Sendai 980
}

\begin{abstract}
Kikuchi, R., Sasaki, H., Nakamura, M. and Takishima, T. Effect of Vagal Tone on Airway Smooth Muscle Force and Peribronchial Pressure in Dogs. Tohoku J. exp. Med., 1982, 136 (2), 157-162 — The main lobar bronchi were isolated airtight from the rest of the lung in excised dog lung. In the relaxed isolated lobar bronchi in excised dog lung, we simulated the percent narrowing of bronchial diameter which was observed with vagus nerves intact and stimulated relative to that with vagus nerves cut (relaxed state). The percent narrowing of bronchi with vagus nerve intact and stimulated were adapted from the data by Hahn et al. (J. appl. Physiol., 41, 581-589, 1976). The forces of airway smooth muscle (Psm) were obtained as the negative intrabronchial pressure ( $\mathrm{Pbr}$ ) when the isolated bronchi were narrowed to the same diameter as those with vagus intact and stimulated, and they were 5 to $10 \mathrm{cmH}_{2} \mathrm{O}$ and 10 to $30 \mathrm{cmH}_{2} \mathrm{O}$, respectively. Peribronchial pressure $(\mathrm{Px})$ was obtained as the difference of $\mathrm{Pbr}$ in the conditions of intact and dissected parenchyma when the diameter of the isolated bronchi were simulated to those with vagus intact and stimulated, and they were positive relative to pleural pressure $(\mathrm{Ppl})$ with vagus cut, negative to $\mathrm{Ppl}$ with vagus stimulated and near zero relative to $\mathrm{Ppl}$ with vagus intact. It was suggested that smooth muscle tone which narrowed the bronchi to the same extent as the diameter with vagus intact made homogeneous expansion between bronchi and lung parenchyma._airway mechanics; parenchymal interdependence; airway hysteresis
\end{abstract}

Airway smooth muscle mechanics was of great interest in the analysis of obstructive lung disease in terms of airway narrowing and control of dead space. Most of the studies in airway smooth muscle mechanics were done in the excised lungs (Olsen et al. 1967; Murtagh et al. 1971; Sasaki et al. 1978). However, the behavior studied in excised dog lungs cannot be directly applied to that in vivo states, because of unknown complications between vagal nerve tone and airway smooth muscle force during ventilatory behavior. Recently Hahn et al. (1976) studied the effect of vagal tone on airway diameter in anesthetized dogs. They suggested that in vivo vagal tone made the airways remarkably independent of lung parenchyma. However, since the airway was greatly influenced by peribronchial parenchyma (Mead et al. 1970; Takishima et al. 1975; Sasaki et al. 1978) it was necessary to study peribronchial pressure $(\mathrm{Px})$ and smooth muscle force during

Received for publication, November 7, 1980.

* To whom correspondences should be addressed. 
vagal nerve stimulation in order to characterize the peribronchial force which determine bronchial diameter.

The purpose of the present study was to better characterize the effect of vagal tone on airway smooth muscle force and $\mathrm{Px}$. Our approach was principally similar to the study by Sasaki and Hoppin (1979). They studied airway smooth muscle force during carbachol-induced constriction in the excised dog lungs. In order to obtain the degree of airway constriction during vagal stimulation, we used the data by Hahn et al. (1976). In the excised dog lungs the main lobar bronchus was isolated airtight from the rest of the lung following the method by Takishima et al. (1975). We measured the isolated bronchial dimensions during lung inflation and deflation and reproduced the same dimensions as reported in vivo dog lungs by Hahn et al. (1976). We inferred Px from the difference of intrabronchial pressure (Pbr) in situ and in the bronchi dissected free from the lung parenchyma. To estimate the bronchomotor tone, we narrowed the isolated bronchi by lowering $\mathrm{Pbr}$ down to the diameters to the same extant as observed under different levels of vagal tone by Hahn et al. (1976). During narrowing the intact bronchi in the same way as the broncho-contracted states in the same dimensions of lung and bronchi, the lowered $\mathrm{Pbr}$ would also directly correspond to an active force of bronchomotor tone.

\section{Materials and Methods}

Five mongrel dogs were anesthetized with sodium pentobarbital $30 \mathrm{mg} / \mathrm{kg}$ intravenously. The dogs were killed by exsanguination and the lungs were immediately removed for use. The right or left lower lobe was used to study the area-pressure behavior of the bronchus in situ. The preparation (Fig. 1) was adapted from that described by Takishima et al. (1975), in which a central portion of the lobar bronchus is isolated from the rest of the lobe by beads glued into the orifices of its branches. Thereby, we were able to measure and control independently the volume and pressures in the isolated portion of the lobar bronchi, $\mathrm{Vbr}$ and $\mathrm{Pbr}$, and in the rest of the lobe, $\mathrm{V}_{\mathrm{L}}$ and $\mathrm{P}_{\mathrm{A}}$, respectively. In order to relax the smooth muscle of the isolated main lobar bonchus, atropine and isoproterenol were administered to final concentrations of $5 \mu \mathrm{g} / \mathrm{ml}$ and $1 \mathrm{mg} / \mathrm{ml}$, respectively.

Because $\mathrm{V}_{\mathrm{L}}$ and $\mathrm{Vbr}$ could be measured and controlled independently in the isolated bronchi, we could reproduce the identical dimensions of the lobe and bronchi in the present preparation with different states of bronchial tone. When this was done, $\mathrm{Pbr}$ was generally more negative with the increase of bronchial tone. With the bronchi and lobe at the same dimensions, this contracted-relaxed $\mathrm{Pbr}$ difference could not have been due to primary changes in the lung parenchymal recoils of the passive elements, but could have resulted from force in the contracted smooth muscle. The pressure difference then represented the inward-acting force due to smooth muscle contraction and was designated as Psm (Sasaki and Hoppin 1979).

The degree of airway constriction with vagal stimulation was adapted from the study by Hahn et al. (1976). They measured bronchial diameter from bronchograms in anesthetized dog lungs with vagus nerve intact, stimulated and cut (relaxed) states during lung inflation and deflation from $\mathrm{P}_{\mathrm{L}} 5$ to $30 \mathrm{cmH}_{2} \mathrm{O}$. From the data by Hahn et al. (1976), we calculated the $\mathrm{Pbr}-\mathrm{Vbr}$ relationships. Fig. 2 shows typical $\mathrm{P}_{\mathrm{L}}-\mathrm{Vbr}$ relations in the preparation simulated to have the airway with vagus nerve cut, intact and stimulated (hereafter simply called with vagus nerve cut, intact and stimulated"). In this figure Vbr was calculated from a percent narrowing of bronchial diameter and bronchial length (Lbr) of the relaxed state in the present preparation. The relaxed state $\left(\mathrm{Pbr}-\mathrm{P}_{\mathrm{A}}=0 \mathrm{cmH}_{2} \mathrm{O}\right)$ 


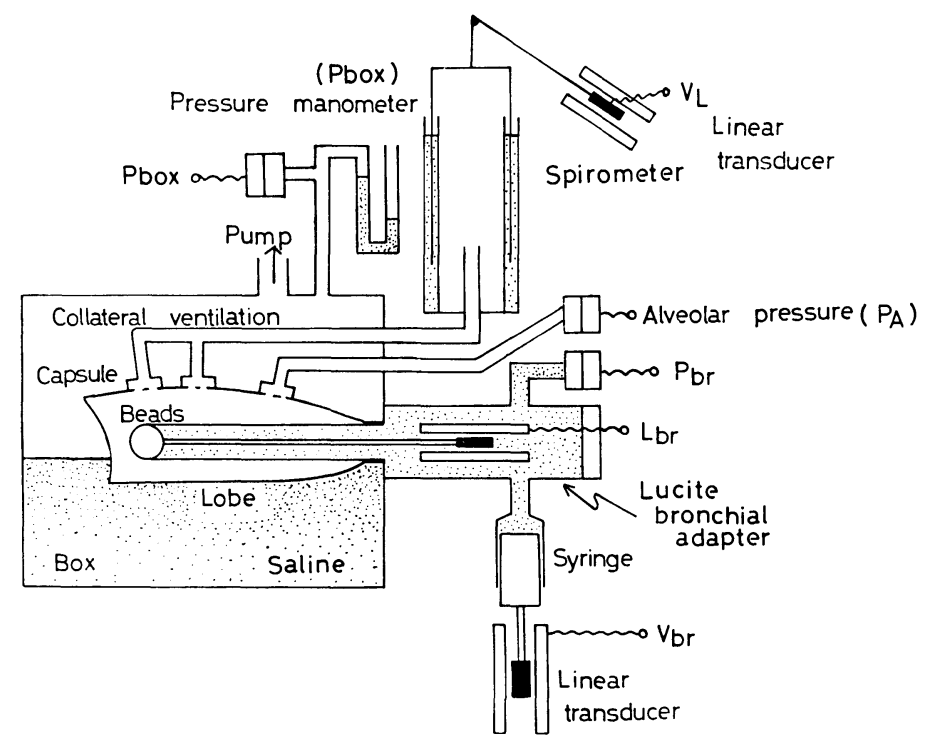

Fig. 1. Block diagram of the apparatus.

The excised lower lobe was laid flat on the saline in the Lucite box. The lung was inflated by negative box pressure (Pbox). The lobar main bronchi were obstructed airtight with beads. The isolated bronchial pressure $(\mathrm{Pbr})$-volume $(\mathrm{Vbr})$ relations were obtained with a pressure transducer and a syringe coupled with a linear displacement transducer, respectively. The isolated lobar main bronchus, the pressure transducer and the syringe were filled with saline. A linear transducer was equipped inside the Lucite bronchial adaptor in order to measure bronchial length (Lbr). Lbr was fixed during bronchial collapse. Two pleural capsules (Takishima et al. 1971) were used for collateral ventilation. Lung volume $\left(\mathrm{V}_{\mathrm{L}}\right)$ was measured with a Benedict-Ross respirometer connected with two pleural capsules. Alveolar pressure $\left(\mathrm{P}_{\mathrm{A}}\right)$ was measured at the third pleural capsule with the pressure transducer. Lung elastic recoil pressure $\left(\mathrm{P}_{\mathrm{L}}\right)$ was defined as $\mathrm{P}_{\mathrm{A}}-\mathrm{Pbox}$.

in the present preparation was assumed to correspond to the state with vagus nerve cut in the preparation by Hahn et al. (1976). At a given $\mathrm{P}_{\mathrm{L}}$, Lbr with both vagus nerve intact and stimulated were fixed to the value in the relaxed state during lung inflation and deflation. With vagus nerve intact and stimulated conditions, we reproduced the isolated bronchial volumes as the corresponding percent decrease of bronchial volumes from relaxed state, using Fig. 2. $\quad$ Vbr- $\mathrm{P}_{\mathrm{L}}$ curves were obtained slowly and continuously taking 2-3 min. during lung inflation and deflation from $\mathrm{P}_{\mathrm{L}} 5$ to $30 \mathrm{cmH}_{2} \mathrm{O}$ in the present preparation.

After completion of all maneuvers in situ, with the lobe and bronchus deflated to ambient pressure, the parenchyma, tributary bronchi, and large vessels were cut away from the bronchial segment. Then, radial traction was due to out side pressure $(\mathrm{Px})$ in the walls on the isolated bronchi. Measurements of $\mathrm{Lbr}, \mathrm{Vbr}$, and $\mathrm{Pbr}-\mathrm{Px}$ were then made on the dissected bronchi during maneuvers in which we attempted to duplicate the sequential bronchial dimensions observed in Fig. 2. Finally, $\mathrm{Px}-\mathrm{P}_{\mathrm{A}}$ was obtained as $\mathrm{Pbr}-\mathrm{P}_{\mathrm{A}}$ in situ minus $\mathrm{Pbr}-\mathrm{Px}$ dissected.

$\mathrm{Vbr}$ and $\mathrm{V}_{\mathrm{L}}$ were recorded by a syringe and a 2 -L Benedict-Ross spirometer connected with linear differential transducers (Sanborn Linearsyn), respectively. Lbr was recorded by a water proof linear differential transducer (Hewlett Packard, 7DCDP-3000). Three 
pressure transducers (Validyne, MP45) measured Pbr, $\mathrm{P}_{\mathrm{A}}$ and $\mathrm{Pbox}$. Vbr-Pbr and $\mathrm{V}_{\mathrm{L}^{-}}$ $\operatorname{Pbox}\left(=P_{L}\right)$ signals were recorded on $\mathrm{X}-\mathrm{Y}$ recorders (Hewlett Packard, 7045A).

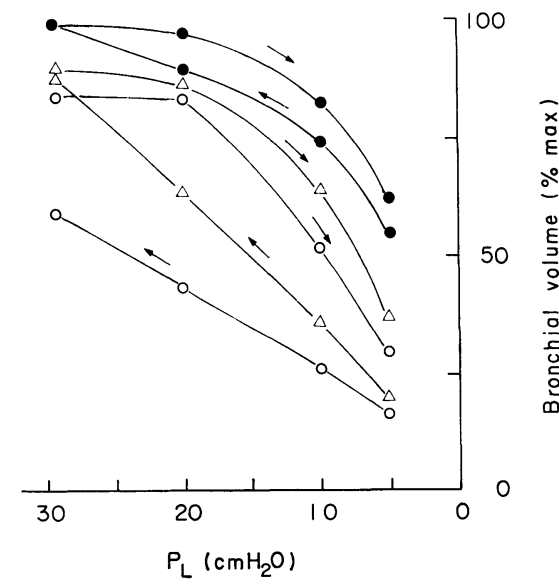

Fig. 2

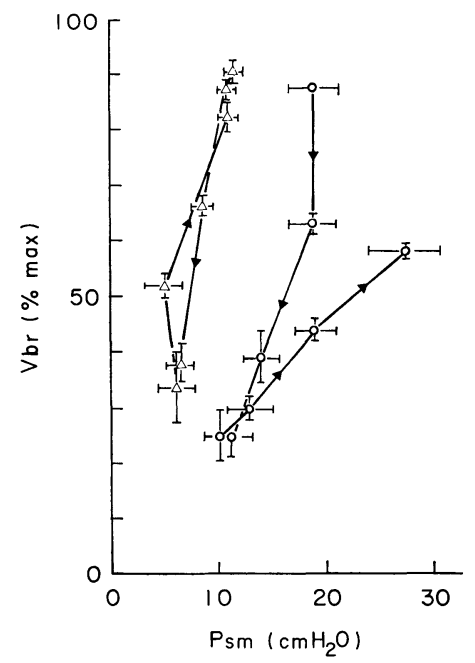

Fig. 3

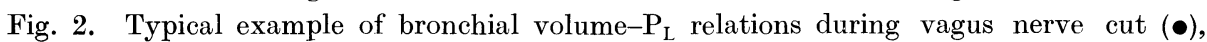
intact $(0)$ and stimulated $(\Delta)$. Curve of relaxed state was from the present preparation. Vbr was calculated from bronchial diameter from Hahn et al. (1976) and bronchial length was obtained from the present preparation. Bronchial volume at $\mathrm{Pbr}=\mathrm{P}_{\mathrm{A}}$ and at $\mathrm{P}_{\mathrm{L}} 30 \mathrm{cmH}_{2} \mathrm{O}$ on the relaxed state was standardized as one hundred percent.

Fig. 3. Active component of bronchial smooth muscle (Psm) to Vbr relationships. Psm were obtained in four different $\mathrm{P}_{\mathrm{L}} 30,20,10$, and $5 \mathrm{cmH}_{2} \mathrm{O}$ and four Vbr-Psm relationships were plotted in each curve. Therefore, at a given airway smooth muscle tone Vbr was larger at higher $\mathrm{P}_{\mathrm{L}}$. Data from five dogs and bars showed mean \pm s.D. Remarks are the same as in Fig. 2.

\section{Results}

Fig. 3 shows Psm to Vbr relationships (mean \pm s.D.) of five dogs. By definition Psm was zero in the relaxed state. With vagus nerve intact Psm was increased from approximately $5 \mathrm{cmH}_{2} \mathrm{O}$ to $10 \mathrm{cmH}_{2} \mathrm{O}$ with increased $\mathrm{P}_{\mathrm{L}}$. Psm showed little hysteresis. With vagus stimulated Psm increased approximately from 10 $\mathrm{cmH}_{2} \mathrm{O}$ to $30 \mathrm{cmH}_{2} \mathrm{O}$ with increased $\mathrm{P}_{\mathrm{L}}$. With decreased $\mathrm{P}_{\mathrm{L}}$, Psm decreased from $20 \mathrm{cmH}_{2} \mathrm{O}$ to $10 \mathrm{cmH}_{2} \mathrm{O}$, so that Psm showed hysteresis. Psm was larger with increased $\mathrm{P}_{\mathrm{L}}$ during vagal nerve stimulation.

Fig. 4 shows $\mathrm{Px}-\mathrm{Ppl}$ to $\mathrm{V}_{\mathrm{L}}$ relationships. If both bronchi and lung parenchyma were expanded homogeneously $\mathrm{Px}-\mathrm{Ppl}$ was zero. With vagus nerve cut during deflation of $\mathrm{V}_{\mathrm{L}}, \mathrm{Px}-\mathrm{Ppl}$ showed near zero except at high $\mathrm{V}_{\mathrm{L}}$ and during inflation of $\mathrm{V}_{\mathrm{L}}, \mathrm{Px}-\mathrm{Ppl}$ showed positive, so that $\mathrm{Px}-\mathrm{Ppl}$ showed a counter-clockwise hysteresis. With vagus nerve stimulated during deflation $\mathrm{Px}-\mathrm{Ppl}$ were almost zero and during inflation $\mathrm{Px}-\mathrm{Ppl}$ were negative at $5-8 \mathrm{cmH}_{2} \mathrm{O}$, so that $\mathrm{Px}-\mathrm{Ppl}$ showed a clockwise hysteresis. With vagus nerve intact there were almost zero $\mathrm{Px}-\mathrm{Pp}$ and negligible hysteresis of $\mathrm{Px}-\mathrm{Ppl}$ during lung inflation and deflation. It was suggested that 


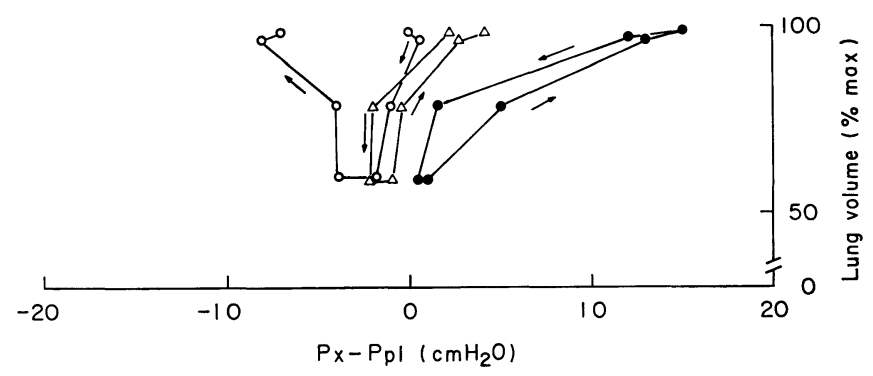

Fig. 4. $\mathrm{Px}-\mathrm{Ppl}$ to $\mathrm{V}_{\mathrm{L}}$ relationships with vagus nerve cut, intact and stimulated. Only mean values were shown for simplicity. Remarks and conditions are the same as in Fig. 3.

vagal tone without stimulation kept the bronchi and lung parenchyma homogeneous during lung ventilation.

\section{Discussion}

The present technique to obtain Psm and Px was the same as used by Sasaki and Hoppin (1979). They constricted bronchi with carbachol. However, carbachol constriction might not be the same as bronchial smooth muscle behavior provided during bronchial constriction with vagal stimulation. Hahn et al. (1976) made bronchographic measurements in the intact anesthetized dog. They reported that diameters with the vagi intact decreased from $95 \%$ of the maximum diameter (diameter bronchodilated at $\mathrm{Pbr}=\mathrm{P}_{\mathrm{A}}$ and at $\mathrm{P}_{\mathrm{L}} 30 \mathrm{cmH}_{2} \mathrm{O}$ ) to $49 \%$ at $\mathrm{P}_{\mathrm{L}} 0 \mathrm{cmH}_{2} \mathrm{O}$. They speculated that since the percent narrowing of airway diameter was larger at middle and low $V_{L}$ than at high $V_{L}$ an active state of smooth muscle would be maximum at middle or low $\mathrm{V}_{\mathrm{L}}$, but not at high $\mathrm{V}_{\mathrm{L}}$. It was speculated that deep inflation canceled bronchoconstriction in human subjects (Nadel and Tierney 1961). In contrast, Sasaki and Hoppin (1979) made bronchoconstriction with carbachol. They found that Psm did not fall off at high $\mathrm{V}_{\mathrm{L}}$ under the stimulation by carbachol while Psm showed a slight peak under the stimulation of electrical field stimulation at the corresponding airway smooth muscle length. Sasaki and Hoppin (1979) suggested that airway hysteresis was greatly determined by both shortening velocity of airway constriction and yielding phenomenon when smooth muscle was extended over a threshold force. Shortening velocity of smooth muscle might be different in the cases between carbachol and vagal stimulation. Therefore, Psm and Px with vagus intact in vivo might be quite different from what obtained in vitro. However, Fig. 3 showed unexpected Psm from the speculation made by Hahn et al. (1976). That is, Psm were always larger at higher $P_{L}$. The principal difference between the results made by Hahn et al. and the present study was that they speculated the behavior of Psm from the behavior of bronchial diameter. With vagus intact, airway smooth muscle has considerable force. Smooth muscle has a basic tone in its control state and does not relax unless smooth muscle was dilated actively. 
$\mathrm{Px}-\mathrm{Ppl}$ is primarily determined by the relative size between bronchi and lung parenchyma. We obtained greatly negative $\mathrm{Px}-\mathrm{Ppl}$ with vagus stimulation. Furthermore, we observed the hysteresis of $\mathrm{Px}-\mathrm{Ppl}$ during lung inflation and deflation. We found the hysteresis of $\mathrm{Pb}-\mathrm{Ppl}$ were quite different depending on bronchomotor tone. In other words, the relative size between bronchi and lung parenchyma was different during lung ventilation. In a relaxed state during lung inflation bronchi were easier to expand than lung parenchyma. This is probably due to large hysteresis of lung parenchyma because of lung surface tension. On the other hand, in a constricted state during lung inflation bronchi were more difficult to expand than lung parenchyma. This is probably due to large resistivity to expand once contracted at a given smooth muscle length. However, once smooth muscle was greatly expanded, probably due to yielding phenomenon of contractile segment of contracted smooth muscle, Psm did not show a further increase. During shortening of smooth muscle, Psm were near zero at high lung volume and Psm increased again at lower lung volume. Therefore, $\mathrm{Px}-\mathrm{Ppl}$ during lung deflation would have more positive value than during lung inflation. Hahn et al. (1976) observed that with vagus stimulated the bronchial diameter showed hysteresis, that is, more resistive to lung inflation than deflation. In the present study, we showed the $\mathrm{Px}-\mathrm{Ppl}$ quantitatively.

With vagi intact both during inflation and deflation $\mathrm{Px}-\mathrm{Ppl}$ was almost near zero and negligible hysteresis, which suggested that both bronchi and lung parenchyma expanded equally independent of various ventilation. Interstitial pressure represented by $\mathrm{Px}$ in the present preparation would influence the lymph flow and interstitial fluid. Homogeneous expansion of the lung at any condition might benefit the even distribution of lymph flow and interstitial fluid which was controlled by the vagus nerve to a subtle extent.

\section{References}

1) Hahn, H.L., Graf, P.D. \& Nadel, J.A. (1976) Effect of vagal tone on airway diameters and on lung volume in anesthetized dogs. J. appl. Physiol., 41, 581-589.

2) Hyatt, R.E. \& Flath, R.E. (1966) Influence of lung parenchyma on pressure-diameter behavior of dog bronchi. J. appl. Physiol., 21, 1448-1452.

3) Mead, T., Takishima, T. \& Leith, D.E. (1970) Stress distribution in lungs: a model of pulmonary elasticity. J. appl. Physiol., 28, 596-608.

4) Murtagh, P.S., Procter, D.F., Permutt, S., Kelly, B.L. \& Evering, S. (1971) Bronchial mechanics in excised dog lobes. J. appl. Physiol., 31, 403-408.

5) Nadel, J.A. \& Tierney, D.F. (1961) Effect of a previous deep inspiration on airway resistance in man. J. appl. Physiol., 16, 717-719.

6) Olsen, C.R., Stevens, A.E. \& McLlroy, M.B. (1967) Rigidity of trachea and bronchi during muscular constriction. J. appl. Physiol., 23, 27-34.

7) Sasaki, H. \& Hoppin, F.G., Jr. (1979) Hysteresis of contracted airway smooth muscle. J. appl. Physiol: Respirat. Enivron. Exercise Physiol., 47, 1251-1262.

8) Sasaki, H., Hoppin, F.G., Jr. \& Takishima, T. (1978) Peribronchial pressure in excised dog lungs. J. appl. Physiol: Respirat. Environ. Exercise Physiol., 45, 858-869.

9) Takishima, T., Sasaki, H. \& Sasaki, T. (1975) Influence of lung parenchyma on collapsibility of dog bronchi. J. appl. Physiol., 38, 875-881.

10) Takishima, T., Ishikawa, K., Sasaki, T., Sasaki, H. \& Nakamura, T. (1971) Measurement of collateral flow at quasi-alveolar level in excised dog lung. Tohoku J. exp. Med., 105, 405-406. 